\title{
Translation and Multilingualism
}

Smita Agarwal

\begin{abstract}
My paper looks at translation and the major concerns of translation theory from the standpoint of a contemporary practitioner creatively involved with languages and culture. I first broach the contentious issue of "mother" vs. "other" tongue and illustrate my own unique multilingual situation and quite unintentional plurilingual education. I also investigate the question of language hegemony and ask if there is, at all, a language of privilege and power for a multilingual person who has acquired languages aurally, from listening and music, without having acquired them in a studied, formal, academic manner. The third part of my paper takes up translation, intertextuality and transcreation with reference to a Bhojpuri folk song and my own published poem in English, "My Bindi". I conclude by discussing my published Hindi translation of Sylvia Plath's "Mirror", which I have termed "aural translation".
\end{abstract}

My mother never fails to embarrass me no end by narrating an incident regarding my preoccupation and special relationship with languages. According to her, when I was five, I was helping her clean a cupboard one afternoon. The task involved removing articles, dusting them, and putting them back in the cupboard. After a short while my interest and inclination waned, and I stood in front of her and said in English, "Mummy, my elephant is paining ...". Upon her cautious enquiry as to what "my elephant" was, I am supposed to have waved my hands and said in Hindi, "Oh, ho! mera toh haath hi darad kar rahaa hai." No translator worth her salt would covet the ease with which I had negotiated from haath hi to haathi to elephant. Unable to distinguish the niceties of idiomatic expression, the child had accomplished one of her first feats of literal translation. 
I seriously wonder whether I have a mother tongue. The situation for me regarding languages was as promiscuous as the person from India who works in Brazil, marries a Brazilian, and produces a child in Brazil, then divorces and goes to Australia, marries an Australian, and produces a child there, then again divorces, relocates, and reproduces .... . What is the relevance and the hold of the mother tongue in such a situation? As far as I can recollect, several languages fell upon my ear simultaneously. My grandparents spoke to me in Garhwali and Hindi; my parents spoke to me in Hindi and English; the servants, particularly my ayah, spoke to me in Dehati; I rattled off film songs in Hindi. The first languages to tickle my eardrums were Garhwali, Hindi, English, and Dehati. All came to me at one and the same time. There is no question of any one of them having come first or taken precedence over another.

Then, like all children, I was sent to school. While there the nuns had their way and I learnt and spoke in English, but as soon as I ran out the school gate I was back with all my other languages, including Dehati with the rickshawalla and the chaprasi and my best friend Rameshva, who taught me how to fly a kite.

According to another myth propagated by my mother, by the time I was four my mother, who was herself a singer, had discovered that I had a melodious voice. Thus began my oral-aural education, with Vividh Bharati, Lata Mangeshkar, and "eichak daana beechak daana daney upar daana". By the time I was eight I had learnt colloquial Urdu, from Bollywood and the radio, because I could sing with ease songs from Mughaleazam, such as "Khuda nigebaan ho tumhaara, dharaktey dil ka payaam lelo, utho hamaara salaam lelo ...". Soon I was transliterating into English popular film songs for uncles and cousins whose Hindi was weak but who desired the lyrics. My formal education in music began and I was singing Meera bhajans in Rajasthani, folk songs in Bhojpuri and Garhwali, badaa khayal and chota khayaal in dialect and vernacular, Faiz and Ghalib in Urdu, the Beatles, Abba and the Carpenters in English .... . Tell me, can a single language stake a claim over one as promiscuous as I? 
The point I am trying to make is that I have grown up in a multilingual environment. Apart from my formal school education in English I have also been educated in non-formal ways, thus acquiring, quite unintentionally, a plurilingual education. Legally you may say my mother tongue is Garhwali, or, perhaps, Hindi, but I am comfortable and at home with many other Indian languages and dialects. These make me multilingual and empower me in ways that amaze me. Hence, I am not conflicted about "mother" and "other" tongues since I learned several languages simultaneously.

Given my peculiar situation with languages, can there be a question of language hegemony for me? Is there at all a language of privilege and power for me, or am I shrewd enough to tweak the situation in my favour as and when required? It is not the languages I know that control me but I them. Assessing the situation, I bring into play the language most suited to the occasion.

Now let me try to focus on how I think my brain works with languages when I create a poem, in this case "My Bindi" (Agarwal 2009):

\section{My Bindi}

All said and done, at fifty, dear bindi, you brighten up

the day ...

Each morning, I've something to look forward to in the mirror, and a game to play ...

Which one of you shall I use today?

A full-stop of red to keep the ardent lover at bay?

An asterisk of gold for the one I wish to amuse? The black exclamation mark for those curious to learn how I juggle 
fidelity with occasional flings?

Mark of the Hindu; fashion-statement

ever since Madonna took to you;

symbol of wedlock or mere

facial embellishment, dumb bindi,

eloquent in your shapes ...

My morse code of dots and dashes,

bindi, that flashes

the one I wish to invite ...

The idea of the poem in English germinated from a Bhojpuri folk song I often sing: "Surajmukh naa jaibey, naa jaibey, hai Rama/Ki mori bindiya ke rang udaa jaaye ...". Hence, the English poem becomes an example of intertextuality across languages, perhaps the kind Harivansha Rai Bachchan experienced while translating Omar Khayyam from English into Hindi and creating his own Madhushala in Hindi (for an excellent discussion of this see Colonial Transactions by Harish Trivedi, 44-70). This crossfertilization of languages in my mind I find particularly profitable in writing poetry.

Surajmukh ... (A Bhojpuri folk song)

Surajmukh naa jaibey, naa jaibey, hai Rama

Ki mori bindiya key rang udaa jaaey.

Laakh takey ki mori bindiya

Woh toh nandi ka jiyaa lalchavey

Ki ho mori bindiya key rang udaa jaaye

Bindiya peher may niksi anganvaa

Woh toh devraa najariya lagaave

Ki ho mori bindiya key rang udaa jaaye

Bindiya mori piya us bhaave

Woh toh hamraa se kahiyo naa jaaey

Ki ho mori bindiya ke rang udaa jaaey ... 
Is the poem an intercultural translation beyond word for word? Is it something beyond translation, a creative translation, a creative adaptation, a transcreation? Yes, insofar as a successful transcreation adapts attributes in a culturally relevant manner in an attempt to reach the target audience at an emotional and intellectual level. Successful transcreation is based on the thorough knowledge of the local environment, culture, and details specific to that culture and country. The poem may be considered a successful transcreation of ideas. Like the Bhojpuri voice, the English one too is subversive, wicked, amorous, and carefree, but that is where the comparison stops, mainly due to differences in culture. The protagonist of the Bhojpuri poem remains bashful and within the ambit of family and tradition, whereas the speaking voice of the English poem achieves a far greater freedom. However, despite all this agonizing about intertextuality and transcreation, "My Bindi" is an original poem in English because it remains accessible to readers in English not at all aware of Bhojpuri culture or Indian traditions of marriage.

\section{Mirror}

I am silver and exact. I have no preconceptions.

Whatever I see I swallow immediately

Just as it is, unmisted by love or dislike.

I am not cruel, only truthful-

The eye of a little god, four-cornered.

Most of the time I meditate on the opposite wall.

It is pink, with speckles. I have looked at it so long

I think it is a part of my heart. But it flickers.

Faces and darkness separate us over and over.

Now I am a lake. A woman bends over me,

Searching my reaches for what she really is.

Then she turns to those liars, the candles or the moon.

I see her back and reflect it faithfully.

She rewards me with tears and an agitation of hands.

I am important to her. She comes and goes.

Each morning it is her face that replaces the darkness.

In me she has drowned a young girl, and in me an old woman

Rises toward her day after day, like a terrible fish. 
(Plath 1981)

Sylvia Plath's "Mirror" is a poem close to my heart and for a long while I wished to make it mine in Hindi. I envied Plath's talent and ability displayed in the poem; I badly wanted to be able to write something like it. When the opportunity of translating the poem came my way, I pounced on it readily, perhaps feeling that in this manner I would be able to make the poem mine. We often talk of translation as if it is a matter of being faultlessly correct and of exquisite technique. A good translation certainly is these things, but there is so much more to it. Ted Hughes, in his notes to the poems of Sylvia Plath mentions that Plath was a conscious artist and most of her well-known poems have a sense of drama because she deliberately wrote as if the poem was a performance. She wrote with the reader in mind; she wrote for an audience; and, as she herself mentions in one of her letters, the "aural" element of the poem, the way it is heard by the reader, was important to her. I decided to let this be my guide while translating. The dramatic qualities of "Mirror" had to be preserved, hence the tone (deadpan, ironic) and the rhythm had to be translated together with the sense meaning. I would not be reading the poem as words on a page; instead, I would be listening to it as a system of sounds and meaning, exactly the way I learn a song from my music teacher.

"I am silver and exact. I have no preconceptions": "Mai rupehla aur sateek. Meri koi purvadharnayein". The word "preconceptions" became a sort of auditory icon that brought me to "purvadharnayein". In this translation, I related the sound and semantic elements in my mind, rather than riffling through the pages of a dictionary or thesaurus. In addition to this I turned to the rhythm of the poem embedded in every line. "I am silver and exact", seven syllables in English, became "Mai rupehla aur sateek", seven syllables in Hindi. Similarly, "unmisted by love or dislike", eight syllables, became "prem ya aruchi se aprabhavit", eight syllables in Hindi. As well there are some intuitive interlanguage alliterations, like "preconceptions" and "poorvadharnayein", "cruel" and "kroor", "meditate" and "manan", "drowned" "duboo", "young" "yuvati". Remember, as I said earlier, this is translation by sound, so I do not 
underestimate the importance of alliteration between languages. Lastly, the diction of Plath's "Mirror" is colloquial, following the easy patterns of conversation. I have tried to retain that conversational ease in "Darpan", but I am afraid my Hindi in the poem is not that of everyday chatter. The diction in "Darpan" is klisht - as far as the Hindi is concerned. Words like poorvadharnayein, aprabhavit, mithyavadiyon, pratibimbhit, puruskrit, are not words used in everyday conversation. Besides this, words from Urdu further the promiscuity displayed in this translation: "Jyadatar", "lambe arseh", "asliyat", "shama", "imandari”, "chehra", etc., rub shoulders with Hindi words.

This translation of "Mirror" from English into Hindi relied on the sound value of the rhythmic word. I feel that the rhythmic word has a subtlety that is complex, flexible, and suggestive of infinite possibilities that makes the act of translation less bookish and more spontaneous. Its powers soar beyond the laws of mechanical construction. In the heat of translation, the intellectual sense of the word hums like an undertone in my mind. I almost, but not quite, forget it, and this enables me to come up with the appropriate word in the target language in an instinctive, spontaneous, and unforced manner. Here it may be fruitful for us to cogitate on the essentially primitive nature of language, where sound conveys sense: for example, Rhimjhim, umad-ghumad, pitter-patter, fizzle. This indefinable quality or property in sound to raise certain vibrations in the mind, this suggestive force of language, its sensational concreteness, is an area that needs to be given greater emphasis in the translation of the rhythmic word. For it helps in distilling not only the intellectual value of the word, not only its emotional power, but also its essence or the spirit of the word, and this is most necessary in the translation of poetry. ${ }^{2}$

To conclude I will address the process of decolonization and standardization and its impact on translational activity, by casting an anxious glance at contemporary popular culture ruled by Bollywood. What impact is this culture going to have on literary and academic translational activity? Will we succumb to the infection of the adulteration of languages, or will we have recourse to isolating 
ourselves in a bubble-wrapped chamber? These are the vexing issues that translators of literary works have to sort out.

When I travel to Khajuraho and my local guide explains erotic sculpture to me in Indian English as, "Lady feeling, man exciting, yoga happening ...", I have no problem understanding the man and secretly commend him for the polish with which he has managed to deal with a difficult subject. My blue-blooded English friend by my side, on the other hand, is totally confused and has to turn to me regarding what the guide has just said. Similarly, Bollywood is creating a brand new form of Bhojpuri by penning lyrics such as "Chaati se lagaava laao dear/ Ab th aajaa near ...".

Since we are a multiethnic, multilingual, plural society we are naturally empowered as far as translational activity is concerned. Our oral tradition provides us with the power to negotiate languages instinctively and intuitively, without much theoretical agonizing. This is the area we need to concentrate on. Should we regard translation as a formal, hyperconscious activity, based on theories of language, psychology etc., or, should we, without being overly concerned about the purity of language, breathe freely, go with the flow, and allow indigenous cultures and languages to come together creatively? We already see this happening all around us in spoken and written language with FM radio, text messages, and Bollywood songs, such as "Dil mein mere hai dard-e-disco", "Yeh lazy lamhe ...", "Yeh dil maange more ...", " White white face dekhe/ Dilva beating fast/ Sasura chance maare rel Dil dance maare re ...". In dialect, we listen to "Chaati se lagaava laao dear/ Ab th aajaa near ...". This unselfconscious translational activity blurs boundaries, subsumes hierarchies, and seems to be the way of the future. In our classrooms, meaning becomes clearer when English idioms are translated into Hindi, not semantically, but as parallel ideas. Shakespeare's quibbles and wordplay may be illustrated, for example, by parallels from Kabir like, "Man ka manka pherle, main turat milaa doon tohe ...”. 
Day after day, the layperson is getting adept at blending regional languages and dialects with English, producing an English comprehensible to an Indian but utterly incomprehensible to a nonnative English speaker. It is a trend we in our ivory towers of academia cannot ignore. Should we be purists and shy away from unselfconscious spontaneity or should we allow this infection to impact us in a controlled manner? As translators of literary texts, our prime aim is to be true to the work in hand and not allow it to be diluted, yet our precaution and caution may deaden the spirit of our endeavour. For, languages are alive and organic and so full of the life force that if stifled they will send out alternative branches, shoots, aerial roots, prop roots, and give birth to a new version of themselves.

\section{Note}

1. See Plath Profiles, Vol. 1, 2008, 198. http://www.iun.edu/ plath/vol1/agarwal.pdf

2. Sri Aurobindo was a firm believer in this, and he expanded upon this idea in several of his essays on poetry and translation.

\section{Works Cited}

Agarwal, S. 2009. "My Bindi”. In Indian English Women Poets, ed. A. Rahman and A. Kazi Ansari. New Delhi, Creative Books, 573-574.

Plath, S. 1981. "Mirror". In Sylvia Plath: Collected Poems, ed. Ted Hughes. London, Faber and Faber.

Trivedi, H. 1993. Colonial Transactions: English Literature and English. Calcutta, Papyrus. 